San Jose State University

SJSU ScholarWorks

Master's Theses

Master's Theses and Graduate Research

Fall 2016

\title{
The Moderating Role of Perceived Organizational Support and Perceived Supervisor Support on the Relationship Between Teamwork Behaviors and Affective Commitment
}

Carlie Ann Stephens

San Jose State University

Follow this and additional works at: https://scholarworks.sjsu.edu/etd_theses

\section{Recommended Citation}

Stephens, Carlie Ann, "The Moderating Role of Perceived Organizational Support and Perceived Supervisor Support on the Relationship Between Teamwork Behaviors and Affective Commitment" (2016). Master's Theses. 4779.

DOI: https://doi.org/10.31979/etd.9u7k-vdp6

https://scholarworks.sjsu.edu/etd_theses/4779

This Thesis is brought to you for free and open access by the Master's Theses and Graduate Research at SJSU ScholarWorks. It has been accepted for inclusion in Master's Theses by an authorized administrator of SJSU ScholarWorks. For more information, please contact scholarworks@sjsu.edu. 


\title{
THE MODERATING ROLE OF PERCEIVED ORGANIZATIONAL SUPPORT AND PERCEIVED SUPERVISOR SUPPORT ON THE RELATIONSHIP BETWEEN TEAMWORK BEHAVIORS AND AFFECTIVE COMMITMENT
}

\author{
A Thesis \\ Presented to \\ The Faculty of the Department of Psychology \\ San José State University \\ In Partial Fulfillment \\ of the Requirements for the Degree \\ Master of Science
}

by

Carlie A. Stephens

December 2016 
(C) 2016

Carlie A. Stephens

ALL RIGHTS RESERVED 
The Designated Thesis Committee Approves the Thesis Titled

THE MODERATING ROLE OF PERCEIVED ORGANIZATIONAL SUPPORT AND PERCEIVED SUPERVISOR SUPPORT ON THE RELATIONSHIP BETWEEN TEAMWORK BEHAVIORS AND AFFECTIVE COMMITMENT

by

Carlie A. Stephens

APPROVED FOR THE DEPARTMENT OF PSYCHOLOGY

SAN JOSÉ STATE UNIVERSITY

December 2016

Dr. Howard Tokunaga

Department of Psychology

Dr. Megumi Hosoda

Department of Psychology

Teresa Cappiello

Human Resources Manager 


\title{
ABSTRACT \\ THE MODERATING ROLE OF PERCEIVED ORGANIZATIONAL SUPPORT AND PERCEIVED SUPERVISOR SUPPORT ON THE RELATIONSHIP BETWEEN TEAMWORK BEHAVIORS AND AFFECTIVE COMMITMENT
}

\author{
by Carlie A. Stephens
}

Researchers have identified employee affective commitment as a key indicator of variables that are of great interest to organizations (Mowday, Porter, \& Steers, 1982). Teamwork behaviors have been identified as predictors of affective commitment (Meyer, Stanley, Herscovitch, \& Topolnytsky, 2002). However, very few studies have examined the moderating effect organizational and supervisor support may have on these relationships. The purpose of this study was to examine the moderating effects of perceived organizational support and perceived supervisor support on the relationship between teamwork behaviors and affective commitment. Results of a survey administered to 3,926 employees in a medical device company revealed that both perceived organizational support and perceived supervisor support significantly moderated the relationship between teamwork behaviors and affective commitment, suggesting that employees who experience more cooperation, communication, and collaboration (teamwork behaviors) report higher levels of affective commitment when they feel their contributions are valued by their organizations and supervisors. It is suggested that organizations focus on increasing perceptions of organizational support and supervisor support because support moderates the relationship between teamwork behaviors and affective commitment. 


\section{ACKNOWLEDGEMENTS}

I would like to thank my thesis committee for their unwavering support and

dedication to my success. Howard, thank you for being my thesis chair and providing me with guidance and encouragement throughout my time as a student at San Jose State University and along the path to completing my thesis. Megumi, thank you for your scrupulous attention to detail when reviewing my paper and for all of your help while completing the graduate program. I would also like to thank Teresa Cappiello for motivating me to complete my thesis and advocating for my success.

To my friends, family, and colleagues, thank you for constantly asking, "How's the thesis?" and reminding me to never give up. I am forever grateful to all who encouraged and supported me along the way. 


\section{TABLE OF CONTENTS}

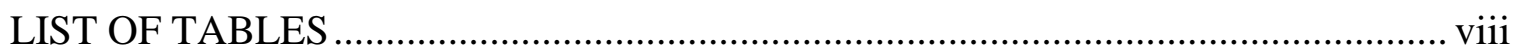

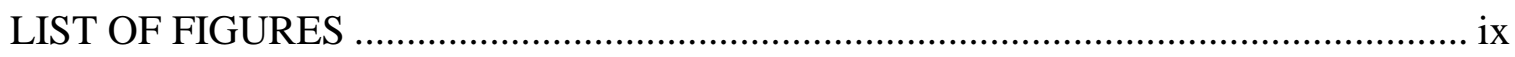

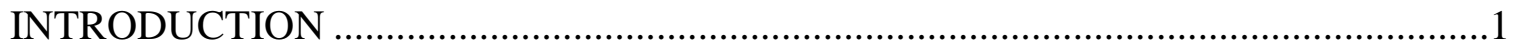

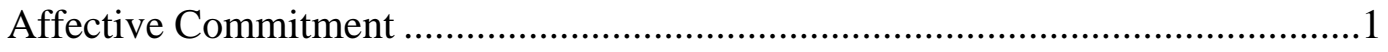

Outcomes of Affective Commitment............................................................

Antecedents of Affective Commitment ..............................................................

Demographic variables .......................................................................

Personality characteristics................................................................

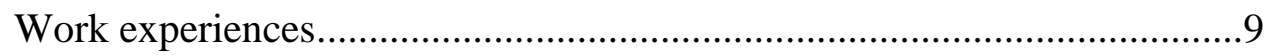

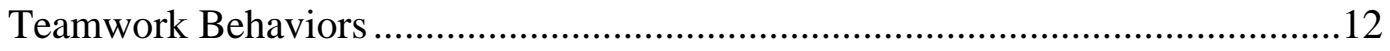

Moderators of the Relationship Between Teamwork Behaviors

and Affective Commitment...................................................................14

Perceived Organizational Support and Perceived Supervisor

Support as Moderators of the Relationship Between

Teamwork Behaviors and Affective Commitment.....................................16

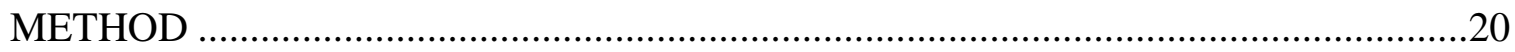

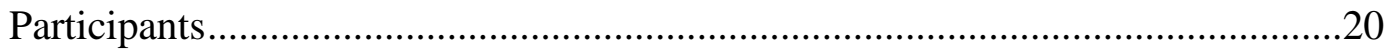

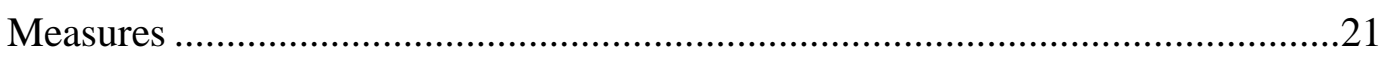

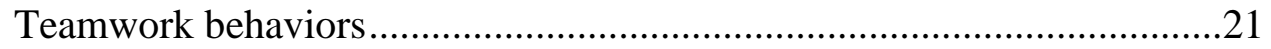

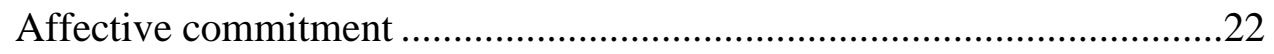

Factor analysis of support items …………………………………......22

Perceived organizational support ...........................................................24

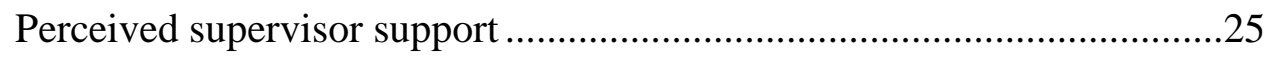




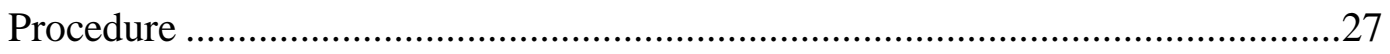

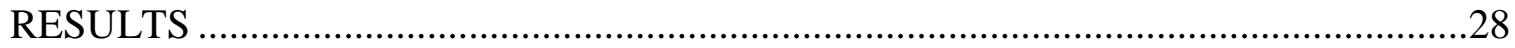

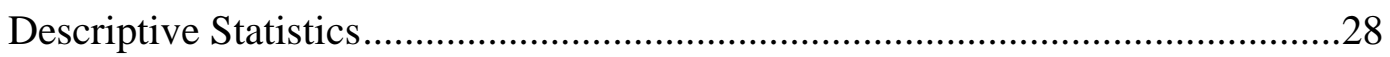

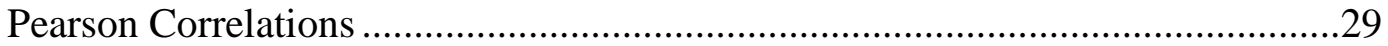

Test of Hypotheses............................................................................... 30

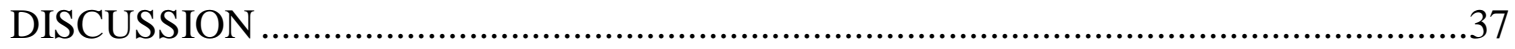

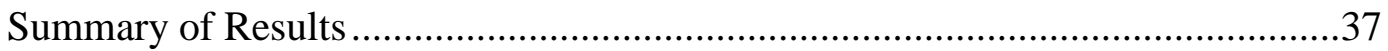

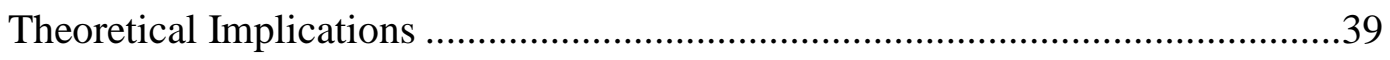

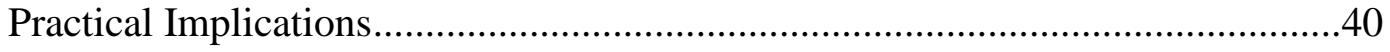

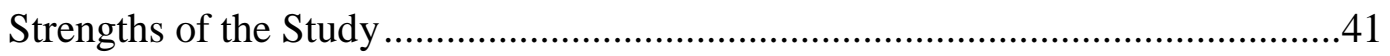

Limitations of the Study and Direction for Future Research .............................42

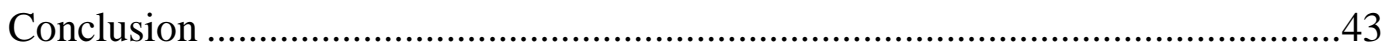

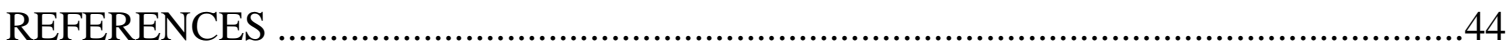




\section{LIST OF TABLES}

Table 1. Demographic Characteristics of Participants...............................................21

Table 2. Factor Analysis: Perceived Organizational Support and

Perceived Supervisor Support Scales........................................................26

Table 3. Means, Standard Deviations, Pearson Correlations, and Cronbach's Alphas

Table 4. Hierarchical Multiple Regression Correlation: Moderating Effect of Perceived Organizational Support ..................................................32

Table 5. Hierarchical Multiple Regression Correlation: Moderating Effect of Perceived Supervisor Support 


\section{LIST OF FIGURES}

Figure 1. Moderating effect of perceived organizational support on the relationship between teamwork behaviors and affective

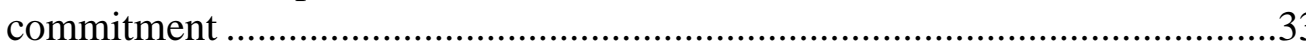

Figure 2. Moderating effects of perceived supervisor support on the relationship between teamwork behaviors and affective

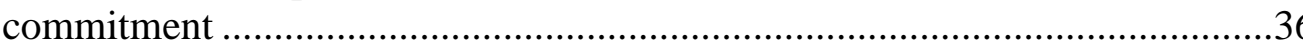




\section{Introduction}

Researchers have identified employee affective commitment as a key indicator of variables that are of great interest to organizations (Mowday et al., 1982). Some key factors that affective commitment predicts include turnover intentions, attendance, organizational citizenship behaviors, and overall productivity (Mathieu \& Zajac, 1990). Because these are highly important variables for organizations, it is equally important to identify variables that contribute to employees' affective commitment. Teamwork behaviors, which consist of actions among team members regarding communication, coordination, and cooperation used to complete team tasks, have been identified as predictors of affective commitment (Meyer et al., 2002). However, very few studies have examined the moderating effect organizational and supervisor support may have on these relationships. The current study examined the moderating effect of perceived organizational support and perceived supervisor support on the relationship between teamwork behaviors and affective commitment. The following sections provide the definition of affective commitment, discuss the consequences and antecedents of affective commitment, present the rationale for perceived organizational support and perceived supervisor support as moderators of the relationship between teamwork behaviors and affective commitment, and present the hypotheses that were tested in the present study.

\section{Affective Commitment}

Organizational commitment has been studied for years and was originally defined as the nature of the relationship of the member to the system as a whole (Grusky, 1966). 
The more commonly adopted definition of organizational commitment is the "strength of an individual's identification with and involvement in a particular organization" (Porter, Steers, Mowday, \& Boulian, 1974, p. 604).

Throughout the years, the definition of organizational commitment has developed to include three dimensions: continuance commitment, affective commitment, and normative commitment. Continuance commitment stems from Becker's (1960) side-bet theory, and is defined as an individual remaining committed to the organization due to an investment in the organization and a perceived loss associated with leaving the organization (Meyer \& Allen, 1984). Essentially, the individual is bound to the organization through extraneous interests rather than favorable affect toward the organization (Porter et al., 1974).

Affective commitment has been defined as an employee's emotional attachment to, identification with, and involvement in the organization (Meyer \& Allen, 1991). This means the employee remains with the organization for its own sake, not solely due to an economic rationale (Meyer \& Allen, 1984). Affective commitment is displayed through an emotional attachment to the organization, sense of belongingness, happiness within the organization, and employees feeling like they are part of a family.

Normative commitment has been defined as an employee's desire to remain in the organization due to feelings of obligation. This means that the employee remains with the organization because the organization may have invested time or resources in the employee and the employee will remain with the organization until the perceived debt has been paid (Meyer \& Allen 1991). 
Continuance commitment, affective commitment, and normative commitment have been portrayed as distinct constructs. However, several studies have questioned the utility of retaining normative commitment due to its high correlation with affective commitment (Ko, Price, \& Mueller, 1997). Because of this, normative commitment was not considered in the present study.

To distinguish between affective commitment and continuance commitment, McGee and Ford (1987) empirically examined the relationship between the two constructs. The researchers distributed the Affective Commitment Scale and the Continuance Commitment Scale to a random sample of faculty at 4-year colleges in the United States. Results of a factor analysis showed a clear distinction between the two scales; inter-scale correlations indicated that the affective commitment and continuance commitment scales had a low, non-significant correlation. Therefore, it was concluded that affective commitment and continuance commitment were distinct constructs and independent dimensions of the larger concept of organizational commitment.

Affective commitment and continuance commitment can also be distinguished by the motivating factors behind each commitment. Affective commitment is believed to be driven by an intrinsic emotional attachment to the organization, whereas continuance commitment is driven by external factors and obligations (Meyer, Allen, \& Topolnytsky, 1998). Affective commitment relies more heavily on work experiences that contribute to employees' comfort in the organization than continuance commitment, which relies more on actions and decisions in or outside of the workplace that affect the value associated with continued employment with the organization (Meyer et al., 2002). Both forms of 
commitment tie closely to an employee's tenure with an organization; however, "given that an employee with strong affective commitment feels emotional attachment to the organization, it follows that he or she will have a greater motivation or desire to contribute meaningfully to the organization...[and] will choose to be absent from work less often and will be motivated to perform better on the job" (Meyer \& Allen, 1997, p.24).

Affective commitment and continuance commitment have been compared with each other in terms of their relationships with relevant criteria. Although both types of commitment have been found to be related to work-related behaviors, affective commitment has been found to be better at predicting job satisfaction and turnover intentions than continuance commitment (McGee \& Ford, 1987; Meyer \& Allen, 1984). Gellatly, Cowden, and Cummings (2014) recently examined affective commitment and continuance commitment among nurses and found that turnover intentions and work relations were more strongly correlated with affective commitment than with continuance commitment. Furthermore, the researchers concluded that when affective commitment was high, nurses were less likely to leave their hospitals regardless of their level of continuance commitment, whereas even if continuance commitment was high, nurses were more likely to leave when affective commitment was low. This relationship was found because affective commitment was influenced by an individual's psychological need to feel comfortable in his or her organization and work role, whereas continuance commitment was influenced by the costs associated with leaving. This difference between affective commitment and continuance commitment is important to note as there 
are various means for increasing commitment, and the motivating factors for each should be considered. Due to the stronger influence of affective commitment than continuance commitment on work-related behaviors, the current study focused only on affective commitment.

\section{Outcomes of Affective Commitment}

Affective commitment has been of interest to many researchers because it is known to predict behaviors of interest to organizations. Some variables that affective commitment predicts include attendance, organizational citizenship behaviors, overall productivity, and turnover intentions (Mathieu \& Zajac, 1990).

Ghorpade, Lackritz, and Moore (2012) looked at the effect of affective commitment on attendance among churchgoers. They examined church attendance as an outcome of church members' identification with and involvement in their congregation. They found that church members with higher levels of affective commitment attended a greater number of church sessions. It was believed that those who had strong emotional attachment to the organization wanted to personally contribute to its success, beyond their normal responsibilities (Meyer \& Allen, 1997). As it may be the most basic component of participation within an organization, it is noteworthy that affective commitment is a predictor of attendance.

Organizational citizenship behaviors are also predicted by affective commitment. Organizational citizenship behaviors are discretionary behaviors extending beyond formal job requirements; examples of these behaviors are helping others, working extra hours, and performing at levels above standards (Smith, Organ, \& Near, 1983). Uçanok 
and Karabati (2013) examined the relationship between affective commitment and organizational citizenship behaviors among employees in small and medium companies with limited resources. From the results, it was concluded that affective commitment had a moderate, significant positive correlation with organizational citizenship behaviors. This means that individuals with higher levels of affective commitment exhibited more willingness to tolerate inconveniences and impositions without complaining, participate in organizational governance, and volunteer to help others. This was found because, according to Wiener (1982), affective commitment was responsible for behaviors that did not depend primarily on reinforcements or punishment.

Affective commitment has also been found to be a predictor of job performance. Schoemmel and Jønsson (2014) examined the effect of affective commitment on job performance as reported by employees. The researchers specifically measured affective commitment towards three different foci: the job, the department, and the organization. The researchers found moderate, significant positive relationships between all three affective commitment foci and self-reported job performance. This means that individuals with higher levels of affective commitment are likely to exhibit more effort on the job, complete more work, and overall perform better than individuals with lower levels of affective commitment. It should be noted that affective commitment to the job was more strongly related to job performance than were affective commitment to the department or organization; this is likely because proximal targets, such as the job, have been found to exert a stronger effect on behavior than distal targets, such as the department or the organization (Becker \& Kernan, 2003). 
Turnover intentions have also been found to be predicted by affective commitment. Vandenberghe and Bentein (2009) found affective commitment to one's organization and affective commitment to one's supervisor had moderate, significant negative relationships with intentions to leave the organization. This means that individuals with higher levels of positive affect towards their organization and supervisors had lower intentions to leave the organization. It should be noted that affective commitment to the organization was more strongly related to turnover intentions than was affective commitment to the supervisor, implying that affective commitment to the organization may be a better predictor of turnover intentions than affective commitment to the supervisor.

In sum, affective commitment has predicted numerous variables that are of interest to organizations. Consequently, it is important to identify constructs that contribute to employees' affective commitment. The next section will outline various antecedents of affective commitment that have been previously studied.

\section{Antecedents of Affective Commitment}

Research has examined the relationship between various factors and affective commitment. Affective commitment has been predicted by several categories of variables, including demographic variables, personality characteristics, and work experiences (Meyer et al., 2002).

Demographic variables. Researchers examined the relationship between demographic variables and affective commitment. Variables that have been found to be positively correlated with affective commitment include age, education, marital status, 
and organization tenure (Meyer et al., 2002). Research has found that older individuals tend to have higher levels of affective commitment (Abdullah \& Shaw, 1999; Day \& Schoenrade, 1997). This is likely because older employees may be more satisfied with their jobs and their positions in the organization and are more likely to develop an emotional attachment to the organization.

Another study found that level of education had a weak yet significant, positive correlation with affective commitment, such that those with more education reported higher levels of affective commitment (Day \& Schoenrade, 1997). Higher levels of education may mean that these individuals are in a more specialized position, which allows them to develop positive affect to the position and to the organization.

Marital status has been found to have a significant, weak, positive relationship with affective commitment, with married individuals more likely to experience higher levels of affective commitment than those who were unmarried (Abdullah \& Shaw, 1999). Married individuals may experience higher levels of affective commitment because they are already primed to have higher levels of commitment due to their marriage. According to the identity theory (Stryker, 1968), it is believed that individuals with commitment to one role (i.e., their marriage) are likely to exhibit higher levels of commitment to another role (i.e., their work or organization).

Personality characteristics. Researchers have also examined the relationship between personality characteristics and affective commitment. One characteristic that has been of interest to researchers is locus of control, which is defined as the extent to which individuals believe they can control events affecting them (Spector, 1988). 
Researchers have found a significant relationship between locus of control and affective commitment, implying that people who believe they can control events in their lives (internal locus of control) tend to have higher levels of affective commitment than those who believe things happen to them regardless of their actions (external locus of control) (Irving \& Coleman, 2003). In general, people with an internal locus of control are predisposed to perceive the work environment more positively and therefore may have higher levels of affective commitment than individuals with an external locus of control, who are predisposed to perceive the work environment more negatively (Judge, Locke, \& Durham, 1997).

Work experiences. Researchers have also examined the relationship between various work experience variables and affective commitment. Of particular interest were variables related to an individual's role within the organization such as role ambiguity and role conflict, variables that focus on processes in the organization such as interactional justice and procedural justice, and variables that pertain to relationships within the organization such as transformational leadership. Work experiences are of interest because they have been found to be stronger predictors of affective commitment than demographic variables or personality characteristics (Meyer et al., 2002).

Factors related to one's role within the organization have been examined as predictors of affective commitment. The relationship between role ambiguity and affective commitment was examined in a study among correctional staff at a maximumsecurity prison (Lambert, Kelley, \& Hogan, 2012). Role ambiguity was defined as a lack of clarity about how to perform one's job duties. The researchers found that role 
ambiguity had a strong, significant, negative relationship with affective commitment, meaning that individuals who were unclear about their job duties had lower levels of affective commitment.

Role conflict, defined as behaviors, duties, and directions for a job being inconsistent with one another (Rizzo, House, \& Lirtzman, 1970), is another job characteristic that has been of interest to researchers. Role conflict has been found to have a stronger, significant negative correlation with affective commitment than role ambiguity (Lambert, et al., 2012). This means that employees with similar behaviors and directions throughout their job duties tend to have higher levels of affective commitment than those with conflicting behaviors, directions, and duties. Conflicting behaviors, directions, and duties can lead to frustration for employees, which can lead to strain, reducing the bond between the employee and the organization.

Researchers have also examined the relationship between work experiences related to processes within the organization and affective commitment. Naumann, Bennett, Bies, and Martic (1998) studied the effect of interactional justice on affective commitment. Interactional justice is defined as the degree to which employers interact with employees in a manner that conveys respect, sensitivity, compassion, dignity, and provides explanations for decisions (Bies \& Moag, 1986). In this study, the researchers surveyed skilled trade employees who were recently informed of a layoff. Interactional justice had a strong, significant, positive relationship with affective commitment, implying that individuals who were treated with sensitivity, compassion, and respect throughout the layoff process reported higher levels of affective commitment. 
Ohana (2014) examined the effects of procedural justice on affective commitment. Procedural justice is defined as justice perceptions based on procedures used to make decisions (Leventhal, 1980). Procedural justice focuses specifically on the fairness of procedures within the organization, distinguishing it from interactional justice, which focuses on interactions between individuals. The researcher found that procedural justice had a strong, positive relationship with affective commitment, implying that individuals who perceive fairness of the processes and decisions within the organization have higher levels of affective commitment to the organization. The social exchange theory (Lavelle, Rupp, \& Brockner, 2007) explains this strong relationship, stating that if individuals feel they are being treated fairly and the organization is looking after them, they will return this favorable treatment in the form of increased commitment to the organization.

Researchers have also recently examined how relationships with other people within the organization may affect affective commitment. Kim and Kim (2015) looked at the relationship between transformational leadership, defined as the energizing emotions of leaders to encourage similar emotions in subordinates, and affective commitment. They found transformational leadership had a strong, positive correlation with affective commitment, suggesting that individuals who are exposed to leaders who are inspirational, motivational, and considerate are likely to have higher levels of affective commitment. Through motivation, the leader inspires employees to adopt the shared vision in the organization and consequently, the employees develop higher levels of affective commitment to the organization. 
Researchers recently took a closer look at the effect of work-related relationships on affective commitment by examining the relationship between leader-member exchange and affective commitment (Kim \& Park, 2015). Leader-member exchange (LMX) is defined as a two-way relationship-based approach to leadership that focuses on the quality of the relationship that develops between an employee and his or her supervisor. Leader-member exchange contributes to a communal relationship in which individuals feel a special responsibility for one another and give and receive accordingly. Individuals with high leader-member exchange are likely to display higher levels of affective commitment because their supervisor treats employees well and pays attention to them. Collecting data from 332 employees of a South Korean engine manufacturing company, they found that leader-member exchange had a moderate, positive correlation with affective commitment.

\section{Teamwork Behaviors}

As seen in the study by Kim and Park (2015), the relationship with one's leader can influence an employee's affective commitment. It may be assumed, therefore, that the relationship with one's coworkers can also influence affective commitment. As such, it is believed that teamwork may have an effect on one's affective commitment to the organization.

Teamwork has been defined as any formal and permanent whole of at least two interdependent individuals who are collectively in charge of achieving one or several tasks defined by the organization (Gladstein, 1984). In work team settings, teamwork 
consists of two main categories of behaviors: task work behaviors and teamwork behaviors.

Task work behaviors are defined as tasks specifically related to technical aspects of team accomplishments (Rousseau, Aubé, \& Savoie, 2006). Task work behaviors may be independent of working in a team and could apply to an individual work setting. Task work behaviors are very similar to the tasks performed by individuals on an assembly line. An example of a task work behavior for an assembly line worker is screwing on the bottom of a widget or taping a box for shipment. Assembly line workers complete tasks that contribute to the end result of a product, but their work tends to be independent and does not necessarily require interaction with other members of the team.

Compared with task work behaviors, teamwork behaviors are actions among team members regarding communication, coordination, and cooperation to complete team tasks (Rousseau, Aubé, \& Savoie, 2006). For example, an assembly line worker may change the location of where products are stored after finishing assigned tasks; communicating and coordinating the change in location with other members of the team is a teamwork behavior. Teamwork behaviors are essential to work teams and are displayed in order to ensure collective action. Employees become a true team when they interact with one another via teamwork behaviors.

Researchers recently examined teamwork behaviors as a predictor of affective commitment (Brunetto et al., 2013). They specifically examined teamwork behaviors among 730 nurses at two private hospitals in the United States via an online survey. The researchers hoped to explain why there was a shortage of nurses by examining the nurses' 
commitment to their hospitals and their turnover intentions. As part of a larger study, the researchers hypothesized that nurses' affective commitment was influenced by their teamwork behaviors. Teamwork behaviors were measured in terms of cooperation, communication, and concern for others on the team.

Brunetto et al. (2013) found teamwork behaviors had a positive, significant correlation with affective commitment. This means that nurses who were cooperative, provided constructive feedback, and exhibited helping behaviors were more affectively committed to their hospitals. The findings of this study showed that approximately $50 \%$ of the variance in nurses' commitment to their hospitals and their intentions to leave could be explained by the teamwork behaviors. This means that the relationship between colleagues (i.e., teamwork behaviors) strongly influences individual's commitment to their organization and ultimately their turnover intentions.

\section{Moderators of the Relationship Between Teamwork Behaviors and Affective Commitment}

The relationship between teamwork behaviors and affective commitment has been studied, but very few researchers have examined whether this relationship is moderated by other variables. An exception to this is a study by Sheng, Tian, and Chen (2010), who examined the moderating effect of perceived team support on the relationship between teamwork behaviors and team commitment. Perceived team support refers to the extent to which the team values an employee's contributions and cares about his or her wellbeing. Team commitment has been defined as the strength of an individual's identification with and involvement in a particular team (Sheng et al., 2010). Team 
commitment is similar to organizational commitment, but primarily focuses on commitment to the team.

Sheng et al. (2010) argued that a more specific focus on commitment and support of the team would provide insight regarding the criticality of team interactions on the relationship between team-related behaviors and commitment to the team. Although they hypothesized that teamwork behaviors (measured in terms of coordination, cooperation, and information sharing) would be positively related to team commitment, they also hypothesized that perceived team support would moderate this relationship such that the relationship between teamwork behaviors and team commitment would be stronger when perceived team support is high and weaker when perceived team support is low. One explanation for the moderating effect of perceived team support could be that if team support were not present, the employee would not develop the connection between their behaviors (team behaviors) and their relationship with the team (team commitment).

The results of this study showed that teamwork behaviors had a significant, positive correlation with team commitment, such that individuals who experienced coordination, cooperation, and information sharing with team members were more committed to the team. More importantly, this study also found that perceived team support had a strong moderating effect on this relationship. When individuals perceived that their efforts were valued and their welfare was considered by the team, the positive relationship between teamwork behaviors and team commitments was amplified. When individuals did not have high levels of team support, there was no relationship between teamwork behaviors and team commitment. 


\section{Perceived Organizational Support and Perceived Supervisor Support as Moderators of the Relationship Between Teamwork Behaviors and Affective Commitment}

Given that perceived team support has been found to moderate the relationship between teamwork behaviors and team commitment, it is possible that other types of support could moderate the relationship between teamwork behaviors and affective commitment. The study by Sheng et al. (2010) investigated the moderating effect of perceived team support; however, it is noteworthy that they suggested that "the organization and high-ranking management should pay attention to and show support for the team" (Sheng et al., 2010, p.1304). Consequently, the current study proposes that the concept of perceived team support is similar to perceived organizational support and perceived supervisor support, and argues that perceived organizational support and perceived supervisor support have a similar moderating effect on the relationship between teamwork behaviors and affective commitment.

Perceived organizational support has been defined as employees' global beliefs concerning the extent to which the organization values their contributions and cares about their well-being (Eisenberger, Huntington, Hutchison, \& Sowa, 1986). Perceived supervisor support is defined as employees' general views concerning the degree to which supervisors value employees' contributions and care about their well-being (Kottke \& Sharafinski, 1988).

Perceived organizational support and perceived supervisor support are similar constructs and both have been used as moderators in relationships similar to the one of interest for the current study. For example, Kawai and Mohr (2015) examined the moderating effect of perceived organizational support and perceived supervisor support 
on the relationship between a stressor (role novelty) and a job attitude (job satisfaction). Role novelty refers to the extent to which the tasks and duties of a new role differ from those performed in the past (Black, 1988), and was regarded as a positive job stressor that the researchers expected would be positively related to job satisfaction. However, they also expected perceived organizational support would moderate this relationship. More specifically, they believed perceived organizational support would strengthen the positive effect of role novelty on job satisfaction by highlighting the positive reward of overcoming the obstacles associated with role novelty. They also expected perceived supervisor support to moderate the relationship between role novelty and job satisfaction in a similar way perceived organizational support did. Because supervisors can provide ongoing personal feedback and performance appraisals to provide further exploration of and adjustment to a new role, it was predicted that the relationship between role novelty and job satisfaction would be stronger for those with high than low perceived supervisor support.

The sample in the Kawai and Mohr (2015) study consisted of 125 Japanese expatriate managers in Germany. The researchers found that, as hypothesized, perceived organizational support and perceived supervisor support moderated the relationship between role novelty and job satisfaction. More specifically, the relationship between role novelty and job satisfaction was stronger for individuals with high perceived organizational support and supervisor support, compared with individuals with low perceived organizational support and supervisor support. These results emphasize the importance of organizational and supervisor support and lend insight to the idea that 
organizations and supervisors should consider the importance of an employee's value and well-being in order to increase the impact of predictors on other positive organizational outcomes.

Given that Kawai and Mohr (2015) found that perceived organizational support and perceived supervisor support moderated the relationship between role novelty and job satisfaction, it is possible that perceived organizational support and perceived supervisor support also moderate the relationship between teamwork behaviors and affective commitment. The relationship between role novelty and job satisfaction is similar to that of teamwork and affective commitment because role novelty and teamwork are both individual perceptions and job satisfaction and affective commitment are both intrinsic emotional attitudes. Considering the similarities of these relationships, it is expected that perceived organizational support and perceived supervisor support would have a similar moderating effect on the relationship between teamwork behaviors and affective commitment.

Similar to Kawai and Mohr's (2015) study regarding role novelty and job satisfaction, it is believed that the relationship between teamwork behaviors and affective commitment will be stronger when perceived organizational support and perceived supervisor support are high than when perceived organizational support and perceived supervisor support are low. Support from the organization and from the supervisor is believed to strengthen the positive relationship between teamwork behaviors and affective commitment because individuals who feel supported reciprocate the support, which impacts the relationship between teamwork behaviors and affective commitment to 
the organization. When support is low, it is likely that the relationship between teamwork behaviors and affective commitment is weaker because employees will not be as strongly driven to reciprocate with teamwork behaviors and affective commitment. In addition, according to the social exchange theory, individuals may see that the costs of exhibiting teamwork behaviors and affective commitment are not equal to the rewards associated with being a member of the organization. In this study, the following hypotheses were tested:

Hypothesis 1: The relationship between teamwork behaviors and affective commitment will be moderated by perceived organizational support, in that the relationship between teamwork behaviors and affective commitment will be stronger when there is high perceived organizational support than when there is low perceived organizational support.

Hypothesis 2: The relationship between teamwork behaviors and affective commitment will be moderated by perceived supervisor support, in that the relationship between teamwork behaviors and affective commitment will be stronger when there is high perceived supervisor support than when there is low perceived supervisor support. 


\section{Method}

\section{Participants}

The initial sample consisted of 3,926 employees at a global medical device company, but 304 respondents were removed from the data set due to incomplete data, resulting in a final sample of 3,622 participants. Data were collected at the organization using a company-wide employee survey administered in 2014. All part-time and fulltime employees were invited to participate in the survey. Contract employees were not invited to participate in the survey because they were employees of a temporary agency and not actively employed by the company.

As shown in Table 1, approximately $55 \%$ of the respondents were employed in North America and South America. The rest of the participants were located in various countries with a majority in the Europe, Middle East, India, and Africa (EMEIA) region and the remainder of employees in the Asia Pacific (APAC) region. Employees of any length of service were eligible to participate in the survey. The majority of participants (58\%) had been employed at the company for at least 5 years, indicating that they were well acquainted with the company. 
Table 1

Demographic Characteristics of Participants $(N=3,622)$

\begin{tabular}{|c|c|c|}
\hline Variable & $f$ & $\%$ \\
\hline \multicolumn{3}{|l|}{ Region } \\
\hline Americas & 1,991 & $55.0 \%$ \\
\hline EMEIA & 1,123 & $31.0 \%$ \\
\hline APAC & 508 & $14.0 \%$ \\
\hline \multicolumn{3}{|l|}{ Years of Service } \\
\hline Less than 6 months & 196 & $5.4 \%$ \\
\hline 6 moths-1 year & 194 & $5.4 \%$ \\
\hline $1-2$ years & 341 & $9.4 \%$ \\
\hline $2-5$ years & 798 & $22.0 \%$ \\
\hline 5-7 years & 472 & $13.0 \%$ \\
\hline $7-10$ years & 541 & $14.9 \%$ \\
\hline $10-15$ years & 477 & $13.2 \%$ \\
\hline $15-20$ years & 213 & $5.9 \%$ \\
\hline More than 20 years & 390 & $10.8 \%$ \\
\hline
\end{tabular}

Note:

Americas represents North and South America region

EMEIA represents Europe, Middle East, India \& Africa region

APAC represents Asia Pacific region

\section{Measures}

Teamwork behaviors. Teamwork behaviors were defined as actions among team members regarding communication, coordination, and cooperation to complete team tasks (Rousseau, Aubé, \& Savoie, 2006). Teamwork behaviors were measured with six items, such as "My team identifies and addresses potential problems that could impact quality or lead to oversight," "Our employees are open in admitting, discussing, and learning from mistakes," and "My team members work well together." The response format for the survey items consisted of a 5-point Likert scale of agreement ( 1 = Strongly Disagree, 5 = Strongly Agree). Participant responses were averaged to create an overall 
score ranging from 1 to 5, with higher scores indicating that respondents experienced more teamwork behaviors. Cronbach $\alpha$ was .81 , indicating high reliability of the scale.

Affective commitment. Affective commitment was defined as an emotional orientation or favorable affect to the organization, regardless of its instrumental worth (Meyer \& Allen, 1984). Affective commitment was measured with five items, such as "I enjoy working for this company," "I intend to stay with this company," and "I would recommend the company as a good place to work". The response format for the survey items consisted of a 5-point Likert scale of agreement $(1=$ Strongly Disagree, $5=$ Strongly Agree). Participant responses were averaged to create an overall affective commitment score ranging from 1 to 5, with higher scores indicating respondents experienced higher levels of affective commitment. Cronbach $\alpha$ was .86, indicating high reliability of the scale.

Factor analysis of support items. Using IBM SPSS Statistics, a principal components analysis (PCA) was conducted on 17 items to assess whether the proposed measures of perceived organizational support and perceived supervisor support were successful in identifying unique characteristics of each scale that would justify them as separate constructs (see Table 2). The principal component analysis (PCA) extracted factors based on eigenvalues greater than 1. To make large factor loadings larger and small factor loading smaller within each factor and to have large correlations with a smaller number of factors, rotation was used to make them easier to interpret. Principal components analysis was preferred over factor analysis due to the exploratory nature of the perceived organizational support and perceived supervisor support scale development. 
A varimax (orthogonal) method of rotation was used due to the items in each subscale appearing theoretically uncorrelated with one another.

Kaiser-Meyer-Olkin and Bartlett tests were run as preliminary analyses to test the assumptions that variables were related to each other. These tests justified the factor analysis by determining whether the variables were sufficiently correlated with each other. Bartlett's test of sphericity was significant, $\chi^{2}(136)=36908.33, p<.001$. An examination of the Kaiser-Meyer-Olkin measure of sampling adequacy suggested that the sample was factorable $(\mathrm{KMO}=.96)$. The results of these tests suggest that the factor analysis was justified.

The PCA yielded two components with eigenvalues greater than 1, explaining a total of $58.03 \%$ of the variance in the 17 perceived organizational support and perceived supervisor support items. The criterion for inclusion on component loadings was for the correlation to be $\geq .45$ between an item and a component. Component 1 accounted for $38.58 \%$ of the variance within the perceived organizational support and perceived supervisor support scales, and was the highest percentage of variance accounted for across the two factors. Eleven items loaded onto Component 1, which was generally related to employee perceptions of supervisor support. Component 1 included items with high factor loadings such as "My manager treats employees with respect" (.84), "My manager cares about me as a person" (.81), and "My manager takes ownership and does not place blame on others" (.81). This component was labeled 'Perceived Supervisor Support.' 
Six items loaded onto Component 2, which was related to employee perceptions of organizational support. Component 2 accounted for $19.45 \%$ of the variance within the perceived organizational support and perceived supervisor support scales and included items with high factor loading such as "The company's recognition and reward programs incent outstanding performance" (.73), "Success and innovation are recognized and celebrated" (.72), and "My Personnel Subarea Senior Management keeps employees informed about what is going on in the company" (.66). Component 2 was labeled 'Perceived Organizational Support.'

Perceived organizational support. Perceived organizational support was defined as employees' global beliefs concerning the extent to which the organization values their contributions and cares about their well-being (Eisenberger, Huntington, Hutchison, \& Sowa, 1986). Perceived organizational support, as confirmed with the principal component analysis (PCA), was measured with six items, such as "The company's recognition and reward programs incent outstanding performance," "Success and innovation are recognized and celebrated," and "My Personnel Subarea Senior Management keeps employees informed about what is going on in the company." The response format for the survey items consisted of a 5-point Likert scale of agreement $(1=$ Strongly Disagree, 5 = Strongly Agree). Participant responses were averaged to create an overall perceived organizational support score ranging from 1 to 5 . Higher scores indicate that respondents perceived their organization to be more supportive. Cronbach $\alpha$ was .74 , indicating high reliability of the scale. 
Perceived supervisor support. Perceived supervisor support was defined as employees' general views concerning the degree to which supervisors value the employee's contributions and care about his or her well-being (Kottke \& Sharafinski, 1988). Perceived supervisor support, as confirmed with the principal component analysis (PCA), was measured with 11 items, such as "My manager treats employees with respect," "My manager cares about me as a person," and "My manager takes ownership and does not place blame on others." The response format for the survey items consisted of a 5-point Likert scale of agreement ( $1=$ Strongly Disagree, $5=$ Strongly Agree $)$. Participant responses were averaged to create an overall perceived supervisor support score ranging from 1 to 5 . Higher scores indicate that respondents perceived their organization to be more supportive. Cronbach $\alpha$ was .94 , indicating high reliability of the scale. 
Table 2

Factor Analysis: Perceived Organizational Support and Perceived Supervisor Support Scales $(N=3622)$

\begin{tabular}{|c|c|c|c|}
\hline \multirow[b]{2}{*}{ Item } & \multicolumn{2}{|c|}{ Factor Loading } & \multirow[b]{2}{*}{$h^{2}$} \\
\hline & 1 & 2 & \\
\hline \multicolumn{4}{|l|}{ Perceived Supervisor Support } \\
\hline My manager treats employees with respect. & .84 & .15 & .73 \\
\hline My manager cares about me as a person. & .81 & .31 & .74 \\
\hline $\begin{array}{l}\text { My manager takes ownership and does not place blame on } \\
\text { others. }\end{array}$ & .81 & .22 & .70 \\
\hline $\begin{array}{l}\text { I am comfortable approaching my manager with any work } \\
\text { related concerns. }\end{array}$ & .81 & .16 & .69 \\
\hline $\begin{array}{l}\text { My manager motivates and inspires me to perform at my } \\
\text { very best. }\end{array}$ & .79 & .37 & .76 \\
\hline $\begin{array}{l}\text { I would be comfortable going to my manager if I had a } \\
\text { question or concern about the company's ethics or } \\
\text { compliance practices. }\end{array}$ & .77 & 20 & .63 \\
\hline My manager removes barriers to enable my success. & .76 & .38 & .73 \\
\hline The feedback my manager gives me is useful to me. & .75 & .34 & .68 \\
\hline $\begin{array}{l}\text { My manager is sensitive to cultural differences and beliefs; } \\
\text { shows respect for the beliefs and traditions of others. }\end{array}$ & .75 & 17 & .59 \\
\hline My manager supports my skill and career development. & .66 & .42 & .61 \\
\hline $\begin{array}{l}\text { My manager and I meet at least quarterly to review } \\
\text { progress against my Compass goals. }\end{array}$ & .50 & .35 & .38 \\
\hline \multicolumn{4}{|l|}{ Perceived Organizational Support } \\
\hline $\begin{array}{l}\text { The company's recognition and reward programs incent } \\
\text { outstanding performance. }\end{array}$ & .11 & .73 & .54 \\
\hline Success and innovation are recognized and celebrated. & .22 & .72 & .57 \\
\hline $\begin{array}{l}\text { My Personnel Subarea Senior Management keeps } \\
\text { employees informed about what is going on in the } \\
\text { company. }\end{array}$ & .15 & .66 & .45 \\
\hline I have the information I need to do my job effectively. & .27 & .61 & .44 \\
\hline $\begin{array}{l}\text { I have flexibility in my work schedule to meet both my } \\
\text { business objectives and my personal commitments. }\end{array}$ & .20 & .51 & .30 \\
\hline $\begin{array}{l}\text { I'm empowered to make necessary decisions when } \\
\text { management is absent. }\end{array}$ & .30 & .50 & .33 \\
\hline
\end{tabular}

Note. Participants respond to these items using five response options ( $1=$ Strongly Disagree, $2=$ Disagree, $3=$ Neither Agree or Disagree, $4=$ Agree, $5=$ Strongly Agree) . Items within this analysis were considered to load onto a component if the correlations were $\geq .45$. Component 1 showed an eigenvalues of 8.34 and accounted for $38.58 \%$ of the variance. 


\section{Procedure}

An external vendor was selected to conduct the employee survey on behalf of the organization. All participants received an email inviting them to take the survey, and were provided with a unique link to the vendor's private survey website. The survey duration was one month, and all surveys were completed online at various times. Upon accessing the survey, respondents were given a message explaining the purpose and goals of the survey, including using their aggregate responses to identify opportunities for improvement within the company. The message also reminded respondents of the confidentiality of their responses. All survey submissions were collected when the participant pressed the "submit" button at the end of the survey.

After the survey completion date, the vendor created a dashboard consisting of the survey responses and demographic information. All personally identifying information was removed to ensure confidentiality of the participants' responses and demographic information. With permission of the company and the external vendor, the data set was provided to the researcher. 


\section{Results}

\section{Descriptive Statistics}

Means, standard deviations, and Pearson correlations for the measured variables

are shown in Table 3. Overall, participants reported moderate to high levels of teamwork behaviors $(M=3.79, S D=.63)$ indicating that they experienced communication, coordination and cooperation among team members. Participants also reported high levels of affective commitment $(M=4.04, S D=.74)$ indicating that employees experienced a sense of belonging and happiness within the organization.

Perceived supervisor support scores among employees were relatively high $(M=4.00, S D=.79)$. A mean score of 4 indicated that the employees in the sample perceived that their supervisor cared about their overall well-being and valued their contributions. Perceived organizational support scores among employees were moderate to high $(M=3.67, S D=.64)$ indicating that employees tended to perceive that their organization was supportive, cared about their overall well-being, and valued their contributions. It should be noted that overall perceived supervisor support scores were higher than overall perceived organizational support scores, suggesting that individuals perceived supervisor support differently than they perceived organizational support. 
Table 3

Means, Standard Deviations, Pearson Correlations, and Cronbach's Alphas $(N=3,622)$

\begin{tabular}{llccccc}
\hline \multicolumn{1}{c}{ Variable } & $M$ & $S D$ & 1 & 2 & 3 & 4 \\
\hline 1. Teamwork behaviors & 3.79 & .63 & $(.81)$ & & & \\
2. Affective commitment & 4.04 & .74 & $.60^{* * * *}$ & $(.86)$ & & \\
& & & & & & \\
3. $\begin{array}{l}\text { Perceived organizational } \\
\text { support }\end{array}$ & 3.67 & .64 & $.64^{* * *}$ & $.66^{* * *}$ & $(.74)$ & \\
$\begin{array}{l}\text { Perceived supervisor } \\
\text { support }\end{array}$ & 4.00 & .79 & $.55^{* * *}$ & $.53^{* * *}$ & $.61^{* *}$ & $(.94)$
\end{tabular}

Note. $* p<.05, * * p<.01, * * * p<.001$ (two-tailed)

Reliability coefficients (Cronbach's alpha) are in parentheses along the diagonal.

\section{Pearson Correlations}

As seen in Table 3, teamwork behaviors were positively related to affective commitment $(r=.60, p<.001)$, such that the more employees experienced cooperation and collaboration among team members, the more they exhibited feelings of belongingness and happiness within the organization.

The moderator of perceived organizational support was significantly related to teamwork behaviors and affective commitment. Affective commitment and perceived organizational support had a strong relationship $(r=.66, p<.001)$. This relationship indicated that when employees felt a sense of belonging with the organization, they were also likely to perceive that their organization cared about their well-being and valued their contributions. Teamwork behavior and perceived organizational support were 
significantly, positively related, such that when employees experienced cooperation and collaboration among team members, they were more likely to perceive that their organization cared about their well-being and valued their contributions $(r=.64$, $p<.001)$.

The moderator of perceived supervisor support was also significantly related to the two variables of interest for the study: teamwork behaviors and affective commitment. Teamwork behaviors and perceived supervisor support had a strong relationship $(r=.55, p<.001)$. This relationship indicated that when employees experienced cooperation and collaboration among team members, they were more likely to perceive that their supervisor cared about their well-being and valued their contributions. Affective commitment and perceived supervisor support were also significantly, positively related, such that when employees perceived that their supervisor cared about their well-being and valued their contributions, they also felt a sense of belonging within the organization $(r=.53, p<.001)$.

\section{Test of Hypotheses}

Hierarchical multiple regression (MRC) analyses were used to test Hypotheses 1 and 2. Hypothesis 1 stated that perceived organizational support would moderate the relationship between teamwork behaviors and affective commitment, such that the relationship between teamwork behaviors and affective commitment would be stronger when there is high perceived organizational support than when there is low perceived organizational support. Hypothesis 2 stated that perceived supervisor support would moderate the relationship between teamwork behaviors and affective commitment, such 
that the relationship between teamwork behaviors and affective commitment would be stronger when there is high perceived supervisor support than when there is low perceived supervisor support.

As shown in Table 4, to test the moderating effect of perceived organizational support on the relationship between teamwork behaviors and affective commitment, years of service was entered in the first step as a control variable. Years of service was used as a control variable because in was used as a control variable in previous research. The control variable accounted for $.60 \%$ of the variance in affective commitment $\left(\mathrm{R}^{2}=.006, \mathrm{R}_{\text {adj }}^{2}=.006, F(1,3620)=22.496, p<.001\right)$. This means that years of service contributed to participant's feelings of affective commitment, indicating that participants with more years of service were more likely to experience lower levels of affective commitment.

In the second step, teamwork behaviors and perceived organizational support were entered. The addition of teamwork behaviors and perceived organizational support accounted for a significant amount of variance above and beyond years of service $\left(\Delta \mathrm{R}^{2}=.484, \mathrm{~F}(2,3618)=1717.589, p<.001\right)$. Teamwork behaviors had a significant unique contribution to affective commitment $(\beta=.291, t=18.719, p<.001)$. This finding indicates that participants who reported experiencing higher levels of teamwork behaviors also reported higher levels of affective commitment. Perceived organizational support also had a significant unique contribution to affective commitment $(\beta=.474$, $t=30.621, p<.001)$. This finding indicates that participants who reported higher levels of perceived organizational support also reported higher levels of affective commitment. 
It should be noted that perceived organizational support had a stronger unique contribution to affective commitment than teamwork behaviors. This implies that the perception of support on part of the organization is more important to determining employee affective commitment than are teamwork behaviors.

In the third step of the regression analysis, the interaction between teamwork behaviors and perceived organizational support was entered. This interaction effect accounted for a significant amount of variance above the control variable and direct effects $\left(\Delta \mathrm{R}^{2}=.001, \mathrm{~F}(1,3617)=4.973, p<.05\right)$. Therefore, the relationship between teamwork behaviors and affective commitment was moderated by perceived organizational support.

Table 4

Hierarchical Multiple Regression Correlation: Moderating Effect of Perceived Organizational Support $(N=3,622)$

\begin{tabular}{|c|c|c|c|}
\hline Predictor & $\beta$ & $\mathrm{R}^{2}$ & $\Delta \mathrm{R}^{2}$ \\
\hline Step 1: Control Variable & & $.006 * * *$ & $.006 * * *$ \\
\hline Years of service & $-.079 * * *$ & & \\
\hline Step 2: Direct Effects & & $.490 * * *$ & $.484 * * *$ \\
\hline Teamwork behaviors & $.291 * * *$ & & \\
\hline Perceived organizational support & $.474 * * *$ & & \\
\hline Step 3: Interaction Effect & & $.490 *$ & $.001 *$ \\
\hline $\begin{array}{l}\text { Teamwork behaviors x Perceived } \\
\text { organizational support }\end{array}$ & $-.203 *$ & & \\
\hline
\end{tabular}

Additional analyses were conducted to examine the significant moderating effect of perceived organizational support on the relationship between teamwork behaviors and affective commitment. Two standard regression analyses were conducted to examine the relationship between teamwork behaviors and affective commitment for "high" and 
"low" perceived organizational support. In order to conduct the regression analyses, the perceived organizational support variable was dichotomized using a median split. Figure 1 illustrates that the relationship between teamwork behaviors and affective commitment was stronger for individuals reporting high levels of perceived organizational support, compared with individuals reporting low levels of perceived organizational support.

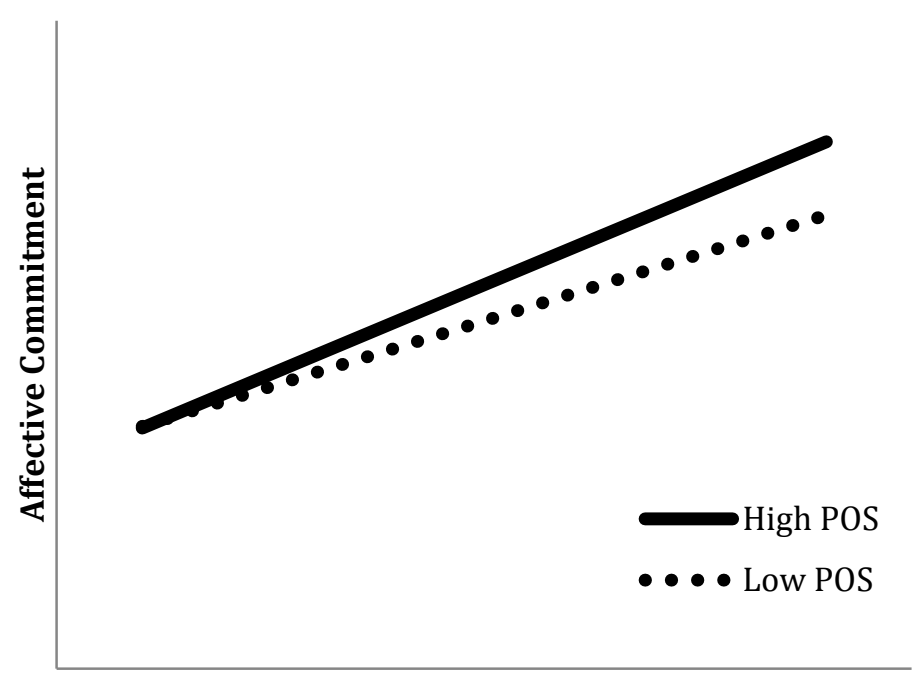

Teamwork Behaviors

Figure 1. Moderating effect of perceived organizational support on the relationship between teamwork behaviors and affective commitment.

A similar hierarchical multiple regression analysis was conducted to test the moderating effect of perceived supervisor support on the relationship between teamwork behaviors and affective commitment (Table 5). Again, years of service was entered in the first step as a control variable. The control variable accounted for .6\% of the variance in affective commitment $\left(\mathrm{R}^{2}=.006, \mathrm{R}^{2}\right.$ adj $\left.=.006, F(1,3620)=22.496, p<.001\right)$. This means that years of service contributed to participant's feelings of affective commitment, 
indicating that participants with more years of service were more likely to experience lower levels of affective commitment.

In the second step, teamwork behaviors and perceived supervisor support were entered. The addition of teamwork behaviors and perceived supervisor support accounted for a significant amount of variance above and beyond the control variable $\left(\Delta \mathrm{R}^{2}=.413, \mathrm{~F}(2,3618)=1287.189, p<.001\right)$. Teamwork behaviors had a significant unique contribution to affective commitment $(\beta=.436, t=28.830, p<.001)$. This finding indicates that participants who reported experiencing higher levels of teamwork behaviors also report experiencing more feelings of affective commitment. Perceived supervisor support also had a significant unique contribution to affective commitment $(\beta=.296, t=19.535, p<.001)$. This finding indicates that participants who report higher levels of perceived supervisor support also reported experiencing more feelings of affective commitment. It should be noted that teamwork behaviors had a stronger contribution to affective commitment than did perceived supervisor support. This implies that teamwork behaviors are more important to determining employee affective commitment than is perceived supervisor support.

In the third step of the regression analysis, the interaction between teamwork behaviors and perceived supervisor support was entered. This interaction effect accounted for a significant amount of variance above the control variable and direct effects $\left(\Delta \mathrm{R}^{2}=.002, \mathrm{~F}(1,3617)=11.307, p<.01\right)$. Therefore, the relationship between teamwork behaviors and affective commitment was moderated by perceived supervisor support. 
Table 5

Hierarchical Multiple Regression Correlation: Moderating Effect of

Perceived Supervisor Support $(N=3,622)$

\begin{tabular}{lccc}
\hline Predictor & $\beta$ & $\mathrm{R}^{2}$ & $\Delta \mathrm{R}^{2}$ \\
\hline Step 1: Control Variable & & $.006^{* * *}$ & $.006^{* * *}$ \\
$\quad$ Years of service & $-.079 * * *$ & & \\
Step 2: Main Effects & & $.419 * * *$ & $.413^{* * *}$ \\
$\quad$ Teamwork behaviors & $.436^{* * *}$ & & \\
$\quad$ Perceived supervisor support & $.296^{* * *}$ & & \\
Step 3: Interaction Effect & & $.421 * *$ & $.002^{* *}$ \\
$\quad$ Teamwork behaviors x Perceived & & & \\
$\quad$ supervisor support & $.302^{* *}$ & & \\
\hline$* p<.05, * * p<.01, * * * p<.001$ & & &
\end{tabular}

Additional analyses were conducted to examine the effect of perceived supervisor support on the relationship between teamwork behaviors and affective commitment. Two standard regression analyses were conducted to examine the relationship between teamwork behaviors and affective commitment for "high" and "low" perceived supervisor support. In order to conduct the regression analyses, the perceived supervisor support variable was dichotomized using a median split. Figure 2 illustrates that the relationship between teamwork behaviors and affective commitment was stronger for individuals reporting high levels of perceived supervisor support, compared with individuals reporting low levels of perceived supervisor support. 


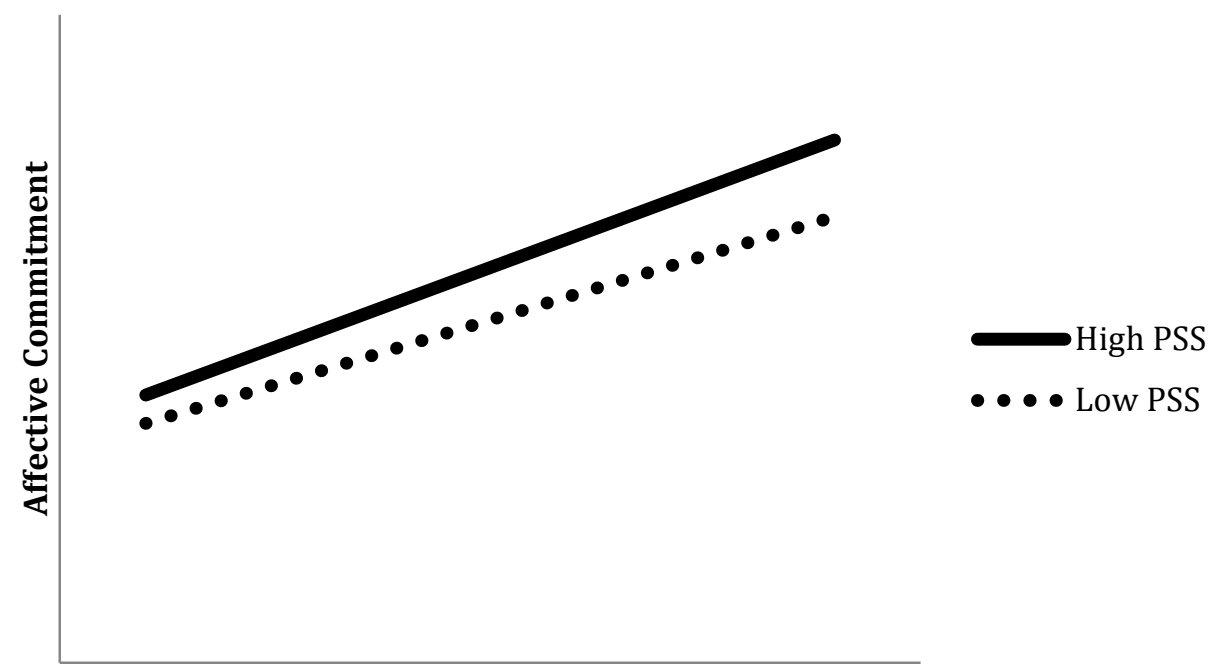

Teamwork Behaviors

Figure 2. Moderating effect of perceived supervisor support on the relationship between teamwork behaviors and affective commitment.

In summary, the results of the multiple regression correlation analyses support

Hypotheses 1 and 2. Results show that individuals who experienced more teamwork behaviors reported higher levels of affective commitment when perceived organizational support was high than when perceived organizational support was low. In addition, individuals who experienced more teamwork behaviors reported high levels of affective commitment when perceived supervisor support was high than when perceived supervisor support was low. 


\section{Discussion}

Affective commitment has been identified as a key predictor of variables of interest to organizations, such as turnover intentions, attendance, organizational citizenship behaviors, and overall productivity (Mathieu \& Zajac, 1990). Due to the high predictive ability of affective commitment, previous studies sought to find possible antecedents of affective commitment. Researchers found that teamwork behaviors were positively correlated with affective commitment (Brunetto et al., 2013; Sheng et al. 2010). The present study sought to expand upon previous research to evaluate whether perceived organizational support and perceived supervisor support would moderate the relationship between teamwork behaviors and affective commitment.

\section{Summary of Results}

Based on the results of the present study, it can be concluded that teamwork behaviors had a significant, positive relationship with affective commitment, meaning that individuals who experienced high levels of teamwork behaviors also experienced increased affective commitment. This finding is consistent with previous studies that found that relationships between colleagues in a team could influence individual's commitment to their organization (Brunetto et al., 2013).

Hypothesis 1 stated that the relationship between teamwork behaviors and affective commitment would be moderated by perceived organizational support, such that the relationship between teamwork behaviors and affective commitment would be stronger when there is high perceived organizational support than when there is low perceived organizational support. Hypothesis 2 stated that the relationship between 
teamwork behaviors and affective commitment would be moderated by perceived supervisor support, such that the relationship between teamwork behaviors and affective commitment would be stronger when there is high perceived supervisor support than when there is low perceived supervisor support. Both hypotheses were supported in the present study.

To test the hypotheses regarding the moderating effects, two hierarchical multiple regression (MRC) analyses were conducted. Results of these analyses showed perceived organizational support and perceived supervisor support each had a significant moderating effect on the relationship between teamwork behaviors and affective commitment. More specifically, employees with higher levels of perceived organizational support and perceived supervisor support were found to have a stronger, positive relationship between teamwork behaviors and affective commitment than employees with lower levels of perceived organizational support and perceived supervisor support, respectively.

The moderating effect of perceived organizational support and perceived supervisor support on the relationship between teamwork behaviors and affective commitment may be explained by social exchange theory. Social exchange theory (Blau, 1964) states that social interactions are built on reciprocal exchanges, which facilitate reciprocity and mutual obligations (Colquitt et al., 2013; Oparaocha, 2015). Based on the social exchange theory, one can assume that as individuals feel more support from the organization or from their supervisor, they would feel the obligation to reciprocate the 
behaviors, which creates a more positive relationship between teamwork behaviors and affective commitment.

\section{Theoretical Implications}

Overall, this study adds to previous literature, as this was the first study to comprehensively examine the moderating effects of perceived organizational support and perceived supervisor support on the relationship between teamwork behaviors and affective commitment. The present study also contributes to previous research by examining these relationships in a global organization.

This study adds to the current body of literature regarding teamwork behaviors and affective commitment by corroborating previous research by Brunetto et al., (2013) demonstrating that teamwork behaviors are related to affective commitment. The present study expanded on previous research by examining teamwork behaviors in a global, cross-functional context, whereas the sample from the research by Brunetto et al. (2013) consisted of only nurses located in the United States.

The present study further contributes to the current body of literature by being the first to examine the moderating effects of perceived organizational support and perceived supervisor support on the relationship between teamwork behaviors and affective commitment. Kawai and Mohr (2015) examined the moderating effects of perceived organizational support and perceived supervisor support in a similar relationship; this study found similar moderating effects that they also found. Furthermore, the present study found that perceived organizational support had a stronger relationship with affective commitment than did perceived supervisor support, and had a stronger 
moderating effect on the relationship between teamwork behaviors and affective commitment, implying that perceived organizational support is more important than perceived supervisor support in predicting affective commitment.

The present study also contributes to the current body of literature regarding the distinction between perceived organizational support and perceived supervisor support. Eisenberger et al. (1986) have argued that supervisors act as agents of the organization, therefore, employees view the supervisor's support (or lack of support) for them as indicative of the organization's level of support, meaning that perceived organizational support and perceived supervisor support are synonymous. In the present study, a high correlation between perceived organizational support and perceived supervisor support was found; also, the two constructs had very similar moderating effects on the relationship between teamwork behaviors and affective commitment. These findings suggest that perceived organizational support and perceived supervisor support may be somewhat redundant, meaning organizations may choose to focus on either organizational support or supervisor support and they would have similar effects in regards to teamwork behaviors and affective commitment.

\section{Practical Implications}

Organizations can use the results of this study to help focus their efforts on increasing employee affective commitment. An important question organizations should be asking is what can be done to encourage employee affective commitment, considering affective commitment is highly predictive of turnover intentions, organizational citizenship behaviors, productivity, and various other variables of interest to 
organizations (Mathieu \& Zajac, 1990). The positive relationship between teamwork behaviors and affective commitment found in this study suggests that one way organizations can increase affective commitment is through increasing teamwork behaviors. Organizations can increase teamwork behaviors such as communication, coordination and cooperation by providing more team building events and increasing face-to-face interactions amongst team members.

It is important to note that in this study the strength of the relationship between teamwork behaviors and affective commitment was found to be greater for employees with high levels of perceived organizational support or perceived supervisor support. This suggests that organizations and supervisors should express value for the employees' contributions and care about the employees' well-being. In order to increase the perceptions of organizational support, organizations should consider providing comprehensive benefits and flexible time off. Organizations can also increase perceived support by recognizing employees for a job well done or encourage autonomy in employees' jobs. In order to increase perceptions of supervisor support, supervisors should express interest in employee well-being and increase face-to-face interaction with employees. Supervisors can also increase perceived support by demonstrating interactional justice among employees, treating employees with respect, and providing opportunities for advancement.

\section{Strengths of the Study}

One of the strengths of this study is that it was conducted using a fairly large representative sample of cross-functional and global employees within a medical device 
company. The vast majority of previous studies that examined a similar relationship focused on one job family or culture, which limits the generalizability of the findings. Looking at this relationship in a global setting allows for better understanding of work relationships and employee affective commitment for global companies.

Another strength of this study was the examination and comparison of the moderating effects of perceived organizational support and perceived supervisor support. Though various studies examined the individual moderating effects of perceived organizational support and perceived supervisor support, the present study allowed for a comparison of the two variables in one sample, which has not been done before.

\section{Limitations of the Study and Directions for Future Research}

A major limitation of the present study was that the variables of interest were highly correlated with one another. This is a limitation because high correlations among the variables likely limited the unique contributions of teamwork behaviors and support on affective commitment. Furthermore, the strong relationship between perceived organizational support and perceived supervisor support indicated redundancy in the moderating effects. Given the high correlations between variables, further research is needed to examine how perceived organizational support and perceived supervisor support moderate the relationship between teamwork behaviors and affective commitment. The results of this study also suggest that a closer conceptual and methodological examination of the difference between perceived organizational support and perceived supervisor support is needed. 
A second limitation was that this study was conducted at a single company in the medical device industry. This may limit the generalizability of the results to other organizations or other industries because some organizations and industries may not rely on or measure the variables of interest such as teamwork behaviors. Future research could benefit from drawing participants from many different organizations to increase the generalizability of its findings.

Another limitation of the study was the scales used to measure the variables of interest. The scales were adopted and accepted as measurements for the variables of interest due to their similarity with other scales and high statistical reliability. However, some scales were measured with fewer items than others, which limits the reliability and subsequently the validity of these scales. Therefore, future researchers should explore more reliable scales for measuring teamwork behaviors, affective commitment, perceived organizational support, and perceived supervisor support.

\section{Conclusion}

Given the various benefits of employee affective commitment, predicting and increasing employee affective commitment is a topic of great interest to organizations. As seen in the present study, teamwork behaviors are indicative of employee affective commitment, and perceived organizational support and perceived supervisor support moderate that relationship. This study corroborates previous research, and expands the current body of literature by examining this relationship in a global, cross-functional context. However, additional research is encouraged to validate and expand upon the findings of this study. 


\section{References}

Abdulla, M. H. A., \& Shaw, J. D. (1999). Personal factors and organizational commitment: Main and interactive effect in the United Arab Emirates. Journal of Managerial Issues, 11, 77-93.

Becker, H. S. (1960). Notes on the concept of commitment. American Journal of Sociology, 66, 32-40.

Becker, T. E., \& Kernan, M. C. (2003). Matching commitment to supervisors and organizations to in-role and extra-role performance. Human Performance, 90, 468-482.

Bies, R. J., \& Moag, J. S. (1986). Interactional justice: Communication criteria of fairness. Research on negotiation in organization, 1, 43-55.

Black, J. S. (1988). Work role transitions: A study of American expatriate managers in Japan. Journal of International Business Studies, 19, 277-294.

Blau, P. W. (1964). Exchange and power in social life. New York, NY: Wiley.

Brunetto, Y., Shriberg, A., Farr-Wharton, R., Shacklock, K., Newman, S., \& Dienger, J. (2013). The importance of supervisor-nurse relationships, teamwork, wellbeing, affective commitment, and retention of North American nurses. Journal of Nursing Management, 21, 827-837.

Colquitt, J. A., Scott, B. A., Rodell, J. B., Long, D. M. Zapata, C. P., Conlon, D. E., \& Wesson, M. J. (2013). Justice at the millennium, a decade later: A meta-analytic test of social exchange and affect-based perspectives. Journal of Applied Psychology, 98, 199.

Day, N. E., \& Schoenrade, P. (1997). Staying in the closet versus coming out: Relationships between communication about sexual orientation and work attitudes. Personnel Psychology, 50, 147-163.

Eisenberger, R., Huntington, R., Hutchison, S., \& Sowa, D. (1986). Perceived organizational support. Journal of Applied Psychology, 71, 500-507.

Gellatly, I. R., Cowden, R. L., \& Cummings, G. G. (2014). Staff nurse commitment, work relationships, and turnover intentions: A latent profile analysis. Nursing Research, 63, 170-181.

Ghorpade, J., Lackritz, J. R., \& Moore, R. (2012). Affective commitment to congregations. Pastoral Psychology, 61, 285-298. 
Gladstein, D. L. (1984). Groups in context: A model of task group effectiveness. Administrative Science Quarterly, 29, 499-517.

Grusky, O. (1966). Career mobility and organizational commitment. Administrative Science Quarterly, 10, 488-503.

Irving, P. G., \& Coleman, D. F. (2003). The moderating effect of different forms of commitment of role ambiguity-job tension relations. Canadian Journal of Administrative Sciences, 20, 97-106.

Judge, T. A., Locke, E. A., \& Durham, C. C. (1997). The dispositional causes of job satisfaction: A core evaluations approach. Research in Organizational Behavior, 19, 151-188.

Kawai, N., \& Mohr, A. (2015). The contingent effects of role ambiguity and role novelty on expatriates' work-related outcomes. British Journal of Management, 26, 163181.

Kim, H., \& Kim, J. (2015). A cross-level study of transformational leadership and organizational affective commitment in the Korean local governments: Mediating role of procedural justice and moderating role of cultural types based on competing values framework. Leadership, 11, 158-185.

Kim, C. Y., \& Park, W. (2015). Emotionally exhausted employees' affective commitment: Testing moderating effects using three-way interactions. Social Behavior and Personality, 43, 1699-1714.

Ko, J. W., Price, J. L., \& Mueller, C. W. (1997). Assessment of Meyer and Allen's threecomponent model of organizational commitment in South Korea. Journal of Applied Psychology, 82, 961-973.

Kottke, J. L., \& Sharafinski, C. E. (1988). Measuring perceived supervisory and organizational support. Educational and Psychological Measurement, 48, 10751079.

Lambert, E. G., Kelley, T., \& Hogan, N. L. (2012). The association of occupational stressors with different forms of organizational commitment among correctional staff. American Journal of Criminal Justice, 38, 480-501.

Lavelle, J., Rupp, D. E., \& Brockner, J. (2007). Taking a multifoci approach to the study of justice, social exchange, and citizenship behavior: the target similarity model. Journal of Management, 33, 841-866. 
Leventhal, G. (1980). What should be done with equity theory? New approaches to the study of fairness in social relationship. Social exchange: Advances in theory and research, New York: Plenum.

Mathieu, J. E., \& Zajac, D. M. (1990). A review and meta-analysis of the antecedents, correlates, and consequences of organizational commitment. Psychological Bulletin, 108, 171-194.

McGee, G. W., \& Ford, R. C. (1987). Two (or more?) dimensions of organizational commitment: Reexamination of the affective and continuance commitment scales. Journal of Applied Psychology, 72, 638-642.

Meyer, J. P., \& Allen, N. J. (1984). Testing the 'side-bet theory' of organizational commitment: Some methodological considerations. Journal of Applied Psychology, 69, 372-378.

Meyer, J. P., \& Allen, N. J. (1991). A three-component conceptualization of organizational commitment. Human Resource Management Review, 1, 61-89.

Meyer, J. P., \& Allen, N. J. (1997). Commitment in the workplace: Theory, research, and application. Thousand Oaks, CA: Sage.

Meyer, J. P., Allen, N. J., \& Topolnytsky, L. (1998). Commitment in a changing world of work. Canadian Psychology/Psychologie canadienne, 39, 83-93.

Meyer, J. P., \& Herscovitch, L. (2001). Commitment in the workplace: Toward a general model. Human Resource Management Review, 11, 299-326.

Meyer, J. P., Stanley, D. J., Herscovitch, L., \& Topolnytsky, L. (2002). Affective, continuance, and normative commitment to the organization: A meta-analysis of antecedents, correlates, and consequences. Journal of Vocational Behavior, 61, 20-52.

Mowday, R. T., Porter, L. W., \& Steers, R. M. (1982). Employee-organizational linkages. New York: Academic Press.

Naumann, S. E., Bennett, N., Bies, R. J., \& Martin, C. L. (1998). Laid off, but still loyal: The influence of perceived justice and organizational support. The International Journal of Conflict Management, 9, 356-368.

Ohana, M. (2014). A multilevel study of the relationship between organizational justice and affective commitment: The moderating role of organizational size and tenure. Personnel Review, 43, 654-671. 
Oparaocha, G. O. (2015). Towards building internal social network architecture that drives innovation: A social exchange theory perspective. Journal of Knowledge Management, 20, 534-556.

Porter, L. W., Steers, R. M., Mowday, R. T., \& Boulian, P. V. (1974). Organizational commitment, job satisfaction, and turnover among psychiatric technicians. Journal of Applied Psychology, 59, 603-609.

Rizzo, J., House, R., \& Lirtzman, S. (1970). Role conflict and ambiguity in complex organizations. Administrative Science Quarterly, 15, 150-163.

Rousseau, V., Aubé, C., \& Savoie, A. (2006). Teamwork behaviors: A review of an integration of frameworks. Small Group Research, 37, 540-570.

Schoemmel, K., \& Jønsson, T. S. (2014). Multiple affective commitments: Quitting intentions and job performance. Employee Relations, 36, 516-534.

Sheng, C. W., Tian, Y. F., \& Chen, M. C. (2010). Relationships among teamwork behavior, trust, perceived team support, and team commitment. Social Behavior and Personality, 38, 1297-1306.

Smith, C. A., Organ, D. W., \& Near, J. P. (1983). Organizational citizenship behavior: Its nature and antecedents. Journal of Applied Psychology, 68, 653-663.

Spector, P. E. (1988). Development of the work locus of control scale. Journal of Occupational Psychology, 61, 335-340.

Stryker, S. (1968). Identity salience and role performance: The relevance of symbolic interaction theory for family research. Journal of Marriage and the Family, 30, $558-564$

Uçanok, B., \& Karabati, S. (2013). The effects of values, work centrality, and organizational commitment of organizational citizenship behaviors: Evidence from Turkish SMEs. Human Resource Development Quarterly, 24, 89-129.

Vandenberghe, C., \& Bentein, K. (2009). A closer look at the relationship between affective commitment to the supervisor and organization and turnover. Journal of Occupational and Organizational Psychology, 82, 331-348.

Wiener, Y. (1982). Commitment in organizations: A normative view. Academy of Management Review, 7, 418-428. 